\title{
VIABILIDADE DE KEFIR COM DIFERENTES MÉTODOS DE INCORPORAÇÃO EM RAÇÃO PELETIZADA
}

\author{
(Viability of kefir with different methods of incorporation in pelleted ration)
}

\begin{abstract}
Bruna Barnei Saraiva ${ }^{1}$, Leandro Dalcin Castilha ${ }^{1}$, Paula Martins Olivo ${ }^{1}$, Bruna Moura Rodrigues ${ }^{1}$, Paulo Cesar Pozza ${ }^{1}$, Magali Soares dos Santos Pozza ${ }^{1}$
\end{abstract}

1Universidade Estadual de Maringá

Corresponding author: bruna_9bs@hotmail.com

RESUMO: A utilização de probióticos na dieta de coelhos melhora o consumo e a digestibilidade dos nutrientes, entretanto pesquisas são necessárias para verificar a melhor forma de sua incorporação na ração. O objetivo do presente estudo consistiu em analisar a utilização de crioprotetores e a viabilidade do probiótico kefir com diferentes métodos de incorporação em ração peletizada para coelhos. Os tratamentos foram: T1 ração controle (sem adição de kefir), T2 ração com kefir in natura dessorado $(6,76 \%)$, T3 kefir dessorado e liofilizado aplicado por banho de óleo após peletização (1\%) e T4 kefir dessorado e liofilizado incorporado anteriormente à peletização (1\%). O delineamento foi em esquema fatorial $4 \times 4$, sendo quatro rações experimentais e quatro tempos de avaliação. Como crioprotetores para a liofilização, foram testados leite desnatado reconstituído (LDR, $12 \%)$ e sacarose (10\%), verificando-se maior número de células sobreviventes para a sacarose (10\%). Após incorporação do probiótico na ração, aos 0, 15, 30 e 45 dias de armazenamento, as amostras foram submetidas à contagem total de bactérias láticas, aeróbios mesófilos, leveduras e coliformes por meio de diluições decimais. A viabilidade das bactérias láticas decresceu de forma significativa $(\mathrm{P}<0,05)$ ao longo da vida de prateleira das rações em todos os tratamentos e a partir do tempo 15 dias não houve contagem significativa $(P>0,05)$ de coliformes nas amostras. A sacarose como crioprotetor propiciou a manutenção de células viáveis de bactérias e leveduras na ração por 45 dias.

Palavras-chave: Crioprotetores; liofilização; microbiologia; probióticos; vida de prateleira.

ABSTRACT: The use of probiotics in the rabbit diet improves nutrient intake and digestibility, however research is needed to verify the best way to incorporate them into the diet. The aim of the present study was to analyze the use of cryoprotectants and the viability of kefir probiotic with different incorporation methods in pelleted feed for rabbits. The treatments were: T1 control diet (without kefir addition), T2 diet with desorphized in natura kefir $(6.76 \%)$, T3 desiccated and lyophilized kefir applied by oil bath after pelletizing (1\%) and T4 desiccated and lyophilized kefir incorporated prior to pelletizing (1\%). The design was a $4 \times 4$ factorial scheme, with four experimental diets and four evaluation times. As cryoprotectants for lyophilization, reconstituted skimmed milk (LDR, 12\%) and sucrose $(10 \%)$ were tested, with a higher number of surviving cells for sucrose (10\%). After incorporation of the probiotic in the diet, at 0, 15, 30 and 45 days of storage, the samples were subjected to total lactic acid, mesophilic aerobic, yeast and coliform count by decimal dilutions. The viability of lactic acid bacteria decreased significantly $(P<0.05)$ over the shelf life of the diets in all treatments and after 15 days there was no significant coliform 
count $(P>0.05)$ in the samples. Sucrose as cryoprotectant allowed the maintenance of viable cells of bacteria and yeast in the diet for 45 days.

Keywords: Cryoprotectants; freeze-drying; microbiology; probiotics; shelf life. 


\section{INTRODUÇÃO}

Têm-se como definição de probiótico microrganismos vivos adicionados à alimentação com o propósito de regular a microbiota intestinal (Fuller, 1989; Santos et al., 2011). Esses microrganismos devem ser habitantes naturais ou transitórios do trato gastrointestinal do hospedeiro, resistentes às condições desfavoráveis da digestão e possuir potencial para habitar a mucosa intestinal (Cook et al., 2012). Podendo desempenhar funções fisiológicas, profiláticas e terapêuticas (Leite et al., 2013). Entretanto, Oliveira (2009) enfatiza que os alimentos funcionais possuem capacidade de favorecer a saúde, e não curar enfermidades.

A bebida kefir é um produto probiótico artesanal obtido após a fermentação de leite em grãos de microflora complexa (Rocha et al., 2014; Dertli e Hilmi, 2017). Estes grãos são compostos pela simbiose entre bactérias ácido láticas, ácido acéticas, leveduras e fungos filamentosos, que fermentam o leite e produzem ácido lático, peptídeos bioativos, exopolissacarídeos e bacteriocinas (Pogačić et al., 2013; Arslan, 2015). Além disso, no processo de fermentação, aproximadamente $30 \%$ da lactose do leite é hidrolisada pela enzima $\beta$-galactosidase, formando glicose e galactose, as bactérias são responsáveis por converter a glicose em ácido lático, provocando a redução do $\mathrm{pH}$ e aumento da viscosidade (Costa e Rosa, 2016).

\section{O Codex Alimentarius (Codex} Stan 243-2003) estabelece que a quantidade mínima de microrganismos totais presentes no leite fermentado produzido pelo kefir deve ser de $10^{7}$ unidades formadoras de colônias (UFC)/mL e $10^{4} \mathrm{UFC} / \mathrm{mL}$ de leveduras (Codex Alimentarius Commission, 2011).

Em coelhos, Attia et al. (2018) afirmam que a utilização de probióticos em rações melhora o consumo e a digestibilidade dos nutrientes. Outro trabalho demonstra que a suplementação de probióticos, mais especificamente Lactobacillus acidophilus $\left(10^{7} \mathrm{UFC} / \mathrm{g}\right)$, além de melhorar a digestibilidade e utilização de nutrientes, aumenta o ganho de peso e conversão alimentar em coelhos chinchilas (Bhatt et al., 2017). Lauková et al. (2016), ao estudarem os efeitos de probióticos em coelhos, concluíram que a linhagem de Enterococcus faecium, aplicada individualmente ou em combinação com Eleutherococcus senticosus, contribuiu para a redução das bactérias de deterioração, aumento da atividade fagocitária e ligeiro aumento no ganho de peso médio diário.

Diante disso, utilizar o kefir como um ingrediente funcional na dieta animal pode proporcionar eventuais benefícios, tais como evitar diarreias, maior bem estar, aumento do desempenho e melhor digestibilidade. Já que a microbiota presente no kefir pode produzir substâncias antagonistas, como ácidos orgânicos e bacteriocinas (Silva et al., 2009), e prejudicar a aderência de bactérias patogênicas na mucosa intestinal (Lauková et al., 2016). Porém há a necessidade de investigar o melhor método de incluir este ingrediente em rações.

$\mathrm{Na}$ fabricação de ração, a temperatura durante $\mathrm{O}$ processo de peletização $\left(60\right.$ a $\left.80^{\circ} \mathrm{C}\right)$ é inferior ao da extrusão $\left(>100^{\circ} \mathrm{C}\right)$, portanto é possível incluir bactérias probióticas antes ou após o processamento. No entanto, é imprescindível o emprego de técnicas que visem proteger os microrganismos e aumentar sua viabilidade. Sendo assim, a liofilização é uma técnica que se baseia na remoção de água por sublimação, método que impede danos celulares em materiais biológicos (Morgan et al., 2006). Garrote et al. (2010) afirmam que a liofilização do kefir 
permite a manutenção da atividade microbiana por 12 a 18 meses.

Objetivou-se avaliar a eficiência de diferentes crioprotetores para a liofilização do produto probiótico kefir de leite, e a viabilidade e sobrevivência de bactérias e leveduras presentes no produto sob diferentes formas de incorporação em ração peletizada para coelhos.

\section{MATERIAL E MÉTODOS}

O experimento foi conduzido no Centro Mesoregional de Excelência em Tecnologia de Leite (CMETL) e na fábrica de rações da Fazenda Experimental de Iguatemi, ambos localizados no distrito de Iguatemi, no Paraná, e pertencentes à Universidade Estadual de Maringá.

Inicialmente, o kefir foi produzido na proporção de $80 \mathrm{~g}$ de grãos para cada litro de leite pasteurizado homogeneizado integral, sendo este leite peneirado (peneira de $2 \mathrm{~mm}$ ) após $24 \mathrm{~h}$ de fermentação $\left(25^{\circ} \mathrm{C}\right)$ em estufa incubadora BOD. Para preparar o produto in natura dessorado, o leite fermentado permaneceu sob refrigeração $\left(10^{\circ} \mathrm{C}\right)$ por $24 \mathrm{~h}$ dessorando em malha $100 \%$ algodão com espessura de fio 24.1, obtendo-se um produto concentrado com maiores contagens microbiológicas. Todos os materiais utilizados na fabricação do produto fermentado e dessorado foram esterilizados.

$\mathrm{Na}$ liofilização, foi utilizado kefir dessorado com diferentes crioprotetores, sendo estes: solução de sacarose $(10 \%)$ e solução de leite desnatado reconstituído (LDR, 12\%). Os crioprotetores foram adicionados na proporção de $50 \% \mathrm{~m} / \mathrm{v}$ em kefir dessorado e as amostras liofilizadas por 48 h. Realizaram-se contagens microbiológicas em Ágar De Man Rogosa e Sharpe (MRS), Ágar Padrão para Contagem (PCA), Ágar YM e Ágar
MacConkey para verificar-se a manutenção da viabilidade celular de bactérias láticas, aeróbios mesófilos, leveduras e coliformes, respectivamente. O crioprotetor mais eficiente, que apresentou maior sobrevivência de bactérias e leveduras, foi utilizado para liofilizar o produto adicionado em ração para coelhos por meio de duas técnicas diferentes: aplicação em superfície por aspersão aquosa com banho de óleo e incorporação no processo de peletização.

Foram avaliados quatro tratamentos: T1 ração controle (sem adição de kefir), T2 ração com kefir in natura dessorado $(6,76 \%)$, T3 kefir dessorado e liofilizado aplicado por banho de óleo após peletização (1\%) e T4 kefir dessorado e liofilizado incorporado anteriormente à peletização $(1 \%)$.

A ração basal foi formulada à base de milho, farelo de soja, farelo de trigo, feno de capim estrela, feno de alfafa, aminoácidos, minerais e vitaminas, atendendo as exigências nutricionais para coelhos em crescimento (De Blas e Mateos, 2010), conforme expresso na Tabela 1. Após a mistura dos ingredientes, a ração foi peletizada a seco, utilizando-se a peletizadora da Indústria Comercial Chavantes, modelo $40 \mathrm{HP}$, com capacidade de 800 a 1.700 $\mathrm{kg} \cdot \mathrm{h}^{-1}$, com matriz de $4,5 \mathrm{~mm}$ e sem adição de vapor, à temperatura média de $70^{\circ} \mathrm{C}\left(60\right.$ a $\left.80^{\circ} \mathrm{C}\right)$, por cerca de 50 segundos.

O probiótico foi diluído em solução de cloreto de sódio $(\mathrm{NaCl}$ 0,9\%), na proporção de $10 \mathrm{~mL}$ de solução para cada $100 \mathrm{~g}$ de ração, possibilitando a inclusão do kefir de forma homogênea por meio de aspersão. As amostras foram secas em estufa com ventilação de ar forçada à $35^{\circ} \mathrm{C}$ por $24 \mathrm{~h}$.

Para o tratamento contendo kefir dessorado in natura (T2), 6,76\% do produto foi adicionado por aspersão, 
diluído em solução de $\mathrm{NaCl}$, essa liofilizado, de acordo com o rendimento proporção equivale à $1 \%$ do produto obtido.

Tabela 1 - Composição percentual e química da ração basal para coelhos em crescimento (na matéria natural).

\begin{tabular}{lc}
\hline \multicolumn{1}{c}{ Ingredientes $^{\prime}$} & Quantidade $(\mathrm{kg})$ \\
\hline Milho grão & 30,00 \\
Farelo de trigo & 24,00 \\
Feno de alfafa & 15,00 \\
Farelo de soja & 14,84 \\
Feno de capim estrela & 13,76 \\
Calcário calcítico & 0,773 \\
Suplemento Vitamínico - Mineral ${ }^{1}$ & 0,500 \\
Sal comum & 0,400 \\
Fosfato bicálcico & 0,290 \\
DL-Metionina & 0,100 \\
L-Lisina HCl & 0,063 \\
Coccidiostático & 0,060 \\
\hline Quantidade total (kg) & 100,00 \\
\hline & \\
\hline Matéria seca (\%) & 88,60 \\
Proteína bruta (\%) & 16,00 \\
Fibra em detergente ácido (\%) & 15,22 \\
Fibra em detergente neutro (\%) & 31,22 \\
Energia digestível (Kcal/kg) & 2.500 \\
Cálcio (\%) & 0,600 \\
Fósforo total (\%) & 0,450 \\
Lisina (\%) & 0,800 \\
Metionina + Cistina (\%) & 0,600 \\
\hline TSuplemento vitamínico-mineral: Composição por kg do produto: vit. A - 600.000 Ul; vit. D - 100.000 \\
Ul; vit. E - 8.000 mg; vit. K3 - 200 mg; vit. B1 - 400 mg; vit. B2 - 600 mg; vit. B6 - 200 mg; vit. B12 - \\
2.000 mcg; ácido pantotênico - 2.000 mg; colina - 70.000 mg; Fe - 8.000 mg; Cu - 1.200 mg; Co - 200 \\
mg; Mn - 8.600 mg; Zn - 12.000 mg; I - 64 mg; Se - 16 mg; Metionina - 120.000 mg; antioxidante - \\
20.000 mg; ${ }^{2}$ Princípio ativo à base de robenidina (6,6\%). \\
\end{tabular}

Para o banho de óleo (T3), após o processo de peletização, $1 \%$ do produto liofilizado foi dissolvido em solução de $\mathrm{NaCl}$ e aplicado sobre a ração por aspersão, em seguida, estas foram recobertas com $16 \%$ de óleo de soja para melhor agregação (Dias et al., 2012). Na ração contendo kefir dessorado e liofilizado incorporado no processo de peletização (T4), o probiótico foi adicionado à $1 \%$ e incorporado com os demais ingredientes da ração antes do processo de peletização.

O armazenamento das rações visou simular sua vida de prateleira, para isso, utilizou-se filme de polietileno (PE) com estruturas laminadas hermeticamente fechadas em seladora, semelhante à embalagens comerciais, com dimensão de $13,5 \mathrm{~cm}$ por $8 \mathrm{~cm}$ e capacidade de conservar $25 \mathrm{~g}$ de amostra, as quais foram abertas nos tempos $0,15,30$ e 45 dias para realização das análises.

As amostras foram submetidas à contagem total de bactérias láticas, aeróbias mesófilas, leveduras e coliformes por meio de diluições decimais e semeadura em triplicata nos meios Ágar De Man Rogosa e Sharpe (MRS), Ágar Padrão para Contagem (PCA), Ágar YM e Ágar MacConkey, respectivamente. Também realizou-se contagem de coliformes no meio Ágar MacConkey para os produtos fermentados e liofilizados. Todas as placas foram incubadas aerobiamente à $37^{\circ} \mathrm{C}$ por 48 horas, exceto o meio Ágar $\mathrm{YM}$, incubado aerobiamente à $30^{\circ} \mathrm{C}$ por 5 dias. 
$\mathrm{O} \mathrm{pH}$ da ração foi mensurado segundo metodologia de Giesting e Easter (1985). Análises de $\mathrm{pH}$ e acidez em triplicata do produto fermentado e liofilizado reidratado foram realizadas segundo Silva et al. (1997). Também calculou-se o rendimento do produto no processo de liofilização, de acordo com a fórmula:

$$
\text { Rendimento }(\%)=\frac{\text { peso após liofilização }}{\text { peso antes da liofilização }} \times 100
$$

Os dados foram analisados utilizando o ProcGLM do SAS 9.1 (2004), avaliando-se os efeitos de tratamentos, tempos e a interação entre tratamento e tempo. As médias foram comparadas pelo teste de Tukey a $5 \%$ de probabilidade.

\section{RESULTADOS E DISCUSSÃO}

Após 24 horas de fermentação $\left(25^{\circ} \mathrm{C}\right)$ e $24 \mathrm{~h}$ dessorando $\left(10^{\circ} \mathrm{C}\right)$, obteve-se um rendimento de $26,53 \%$ de kefir concentrado, os outros $73,47 \%$ consistiram em soro, sendo este descartado.

O kefir pode facilmente ser contaminado devido sua manipulação diária, em razão disso, o produto em pó é vantajoso (Atalar e Dervisoglu, 2015). Segundo Morgan et al. (2006), a liofilização é o melhor método de secagem para microrganismos, devido tornar as culturas viáveis por longos períodos, além de viabilizar o armazenamento e transporte, porém o processo é capaz de causar injúrias ou danos celulares. Witthuhn et al. (2005), observaram redução na contagem e variedade de espécies microbianas após liofilizar e armazenar grãos de kefir. Para prevenir estes prejuízos, sugere-se adicionar substâncias protetoras antes do congelamento e secagem (De Paoli, 2005).

Dentre as substâncias testadas como crioprotetores (sacarose e leite desnatado reconstituído), a solução de sacarose $(10 \%)$ foi selecionada para a liofilização do kefir e este produto adicionado à ração por duas técnicas distintas: aplicação em superfície por aspersão aquosa com banho de óleo (T3) e incorporação no processo de peletização (T4). Esta escolha justificase pela maior sobrevivência dos microrganismos ao processo de liofilização (Tabela 2). Silva et al. (2014), ao testarem sacarose, glicerol e gelatina como crioprotetores em kefir, também constataram que a sacarose $10 \%$ foi mais eficiente para a sobrevivência das culturas de bactérias láticas e leveduras, apresentando contagem de 8 $\log _{10}$ UFC/g e $4 \quad \log _{10} \mathrm{UFC} / \mathrm{g}$, respectivamente.

Tabela 2 - Contagem de microrganismos em $\log _{10}$ UFC/g e rendimento do kefir no processo de liofilização.

\begin{tabular}{lccccc}
\hline Tratamento & PCA $^{1}$ & MRS $^{2}$ & YM $^{3}$ & MacConkey $^{4}$ & $\begin{array}{c}\text { Rendimento } \\
\text { Liofilização (\%) }\end{array}$ \\
\hline Sem crioprotetor & 7,59 & 8,51 & 8,49 & Ausente & 22,67 \\
Sacarose $(10 \%)$ & 8,59 & 8,96 & 8,89 & Ausente & 14,04 \\
LDR $^{5}(12 \%)$ & 8,39 & 8,45 & 8,41 & Ausente & 15,87 \\
\hline
\end{tabular}

${ }^{1}$ bactérias aeróbias mesófilas; ${ }^{2}$ bactérias láticas; ${ }^{3}$ leveduras; ${ }^{4}$ coliformes totais; ${ }^{5}$ leite desnatado reconstituído.

0 produto kefir in natura dessorado apresentou média de 3,96 para $\mathrm{pH}$ e $101^{\circ} \mathrm{D}$ para acidez titulável, enquanto o produto kefir dessorado liofilizado com crioprotetor sacarose $(10 \%)$ expressou valores médios de
4,07 para $\mathrm{pH}$ e $27,6{ }^{\circ} \mathrm{D}$ para acidez titulável. Weschenfelder et al. (2011) verificaram valor semelhante de $\mathrm{pH}$ para kefir in natura, enquanto a acidez foi maior que $140^{\circ} \mathrm{D}$. 


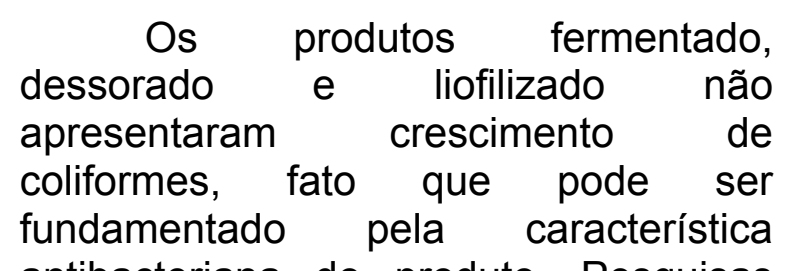
antibacteriana do produto. Pesquisas demonstram que kefir e seu soro são capazes de inibir e inativar Escherichia coli em concentrações menores de $10^{8}$ UFC/mL (Weschenfelder et al., 2009).

$\mathrm{O} \mathrm{pH}$ médio determinado para as rações do tratamento controle ( $T 1$, sem adição de kefir), kefir in natura dessorado (T2), kefir dessorado e liofilizado aplicado por banho de óleo após peletização (T3) e kefir dessorado e liofilizado incorporado anteriormente à peletização foram, respectivamente: $5,90,5,79,5,92$ e 5,82 .

A viabilidade das bactérias láticas decresceu de forma significativa $(P<0,05)$ ao longo da vida de prateleira das rações em todos os tratamentos (Tabela 3). Verificou-se que somente o tratamento contendo o produto liofilizado adicionado antes da peletização apresentou sobrevivência destes microrganismos até 30 dias. Neste mesmo tratamento, observou-se contagem microbiológica inferior das bactérias láticas nos tempos 0 e 15 dias quando comparado aos demais tratamentos (Tabela 3), possivelmente devido injúrias causadas pela temperatura de peletização $\left(70^{\circ} \mathrm{C}\right)$. Rodrigues (2018) sugere que fatores extrínsecos, como oxigênio, temperatura e umidade do meio, são os responsáveis pela perda da viabilidade microbiana durante a vida de prateleira das rações.

O melhor tratamento é representado pelas maiores contagens microbiológicas (Tabela 3), porém as elevadas contagens no tratamento contendo o produto in natura (T2), aos 45 dias, podem estar associadas aos maiores valores de atividade de água (AW). Pois a AW é um parâmetro indicativo da estabilidade dos alimentos e sua redução dificulta a proliferação microbiana (Jay, 2005). Considerando isso, a ração com adição do probiótico liofilizado aplicado por banho de óleo (T3) mostrou-se mais efetiva.

A partir de 15 dias não houve contagem $\quad(P<0,05) \quad$ de coliformes (Tabela 3). Aroutcheva et al. (2001) afirmam que microrganismos isolados de kefir desempenham papel inibidor sobre Staphylococcus aureus, Escherichia coli, Listeria monocytogenes e outros patógenos, embora não haver efeito para tratamento no presente estudo ( $p>0,05)$.

Para calcular a ingestão de probiótico, devemos considerar a associação de bactérias e leveduras, além da ingestão diária de cada espécie animal. O tratamento T3, aos 15 dias, apresentou contagem microbiológica total de 9,53 $\log _{10} \mathrm{UFC} / \mathrm{g}$ de ração. Considerando que o consumo médio diário de um coelho adulto é de $100 \mathrm{~g}$ de matéria seca, a ingestão aproximada de microrganismos probióticos seria de $13,53 \log _{10}$ UFC.

O uso de aditivos na alimentação animal é regulamentado pela Instrução Normativa n44 de 2015 do Ministério da Agricultura, Pecuária e Abastecimento. Para probióticos, é necessário conter no rótulo a identificação das cepas e níveis de garantia, como UFC/g, porém não é definido quantidades mínimas necessárias, mas que o produto esteja presente na quantidade suficiente para exercer função probiótica, a qual deve ser comprovada (Brasil, 2015). 
Tabela 3 - Contagem de microrganismos em $\log _{10} \mathrm{UFC} / \mathrm{g}$ e interações dos diferentes tratamentos experimentais nos diferentes tempos de amostragem.

\begin{tabular}{|c|c|c|c|c|c|c|}
\hline Tratamento & $\begin{array}{l}\text { Tempo } \\
\text { (dias) }\end{array}$ & $\mathrm{PCA}^{1}$ & $\mathrm{MRS}^{2}$ & $\mathrm{YM}^{3}$ & MacConkey ${ }^{4}$ & $A W^{5}$ \\
\hline \multirow{4}{*}{$\mathrm{T} 1^{6}$} & 0 & $4,193^{f} \pm 0,10$ & $<10^{1 f} \pm 0,00$ & $3,893^{\mathrm{fghi}} \pm 0,09$ & $2,200^{a} \pm 0,35$ & $0,535^{i} \pm 0,01$ \\
\hline & 15 & $4,856^{d} \pm 0,05$ & & $5,013^{\mathrm{cd}} \pm 0,07$ & $<10^{2 b} \pm 0,00$ & $0,691^{\mathrm{e}} \pm 0,01$ \\
\hline & 30 & $3,606^{i} \pm 0,06$ & $<10^{1 \uparrow} \pm 0,00$ & $4,000^{\mathrm{fgh}} \pm 0,00$ & $<10^{2 \mathrm{~b}} \pm 0,00$ & $0,707^{\mathrm{de}} \pm 0,00$ \\
\hline & 45 & $3,700^{\mathrm{hi}} \pm 0,04$ & $<10^{1 \uparrow} \pm 0,00$ & $3,833^{\mathrm{fghi}} \pm 0,05$ & $<10^{2 \mathrm{~b}} \pm 0,00$ & $0,589^{9} \pm 0,00$ \\
\hline \multirow{4}{*}{$\mathrm{T}^{7}$} & 0 & $5,303^{c} \pm 0,02$ & $4,790^{b} \pm 0,04$ & $5,920^{b} \pm 0,41$ & $2,160^{\mathrm{ab}} \pm 0,28$ & $0,563^{h} \pm 0,00$ \\
\hline & 15 & $3,846^{\text {hg }} \pm 0,10$ & $3,080^{d} \pm 0,33$ & $3,543^{\mathrm{Jhi}} \pm 0,66$ & $<10^{2 b} \pm 0,00$ & $0,709^{d c} \pm 0,00$ \\
\hline & 30 & $5,143^{c} \pm 0,04$ & $<10^{1 \mathrm{t}} \pm 0,00$ & $4,620^{\mathrm{fde}} \pm 0,03$ & $<10^{2 \mathrm{~b}} \pm 0,00$ & $0,745^{b} \pm 0,00$ \\
\hline & 45 & $6,993^{a} \pm 0,04$ & $<10^{1 \dagger} \pm 0,00$ & $7,120^{a} \pm 0,00$ & $<10^{2 b} \pm 0,00$ & $0,767^{\mathrm{a}} \pm 0,00$ \\
\hline \multirow{4}{*}{$T 3^{8}$} & 0 & $5,720^{\mathrm{b}} \pm 0,02$ & $5,256^{a} \pm 0,02$ & $5,546^{b c} \pm 0,05$ & $<10^{2 b} \pm 0,00$ & $0,563^{h} \pm 0,00$ \\
\hline & 15 & $4,650^{\mathrm{e}} \pm 0,07$ & $3,190^{\mathrm{cd}} \pm 0,21$ & $4,886^{\text {cde }} \pm 0,07$ & $<10^{2 b} \pm 0,00$ & $0,719^{d c} \pm 0,00$ \\
\hline & 30 & $3,683^{\mathrm{hi}} \pm 0,07$ & $<10^{1 \dagger} \pm 0,00$ & $4,126^{\text {fghe }} \pm 0,17$ & $<10^{2 b} \pm 0,00$ & $0,745^{\mathrm{b}} \pm 0,00$ \\
\hline & 45 & $3,153^{\mathrm{j}} \pm 0,04$ & $<10^{1 t} \pm 0,00$ & $3,170^{\mathrm{ji}} \pm 0,02$ & $<10^{2 \mathrm{~b}} \pm 0,00$ & $0,714^{\mathrm{dc}} \pm 0,00$ \\
\hline \multirow{5}{*}{$\mathrm{T} 4^{9}$} & 0 & $3,946^{9} \pm 0,15$ & $3,553^{\mathrm{C}} \pm 0,12$ & $4,033^{\mathrm{fgh}} \pm 0,26$ & $2,493^{a} \pm 0,43$ & $0,547^{\text {ih }} \pm 0,00$ \\
\hline & 15 & $3,786^{\text {hgi }} \pm 0,57$ & $2,043^{\mathrm{e}} \pm 0,18$ & $3,793^{\text {ghi }} \pm 0,37$ & $<10^{2 b} \pm 0,00$ & $0,671^{f} \pm 0,01$ \\
\hline & 30 & $3,863^{\text {hg }} \pm 0,03$ & $1,853^{\mathrm{e}} \pm 0,20$ & $3,000^{\mathrm{j}} \pm 0,00$ & $2,100^{\mathrm{ab}} \pm 0,17$ & $0,726^{\mathrm{c}} \pm 0,00$ \\
\hline & 45 & $3,823^{\text {hg }} \pm 0,03$ & $<10^{1 f} \pm 0,00$ & $4,453^{\text {fgde }} \pm 0,48$ & $<10^{2 b} \pm 0,00$ & $0,726^{\mathrm{c}} \pm 0,01$ \\
\hline & & $\mathrm{PCA}^{1}$ & $\mathrm{MRS}^{2}$ & $\mathrm{YM}^{3}$ & MacConkey ${ }^{4}$ & $\mathrm{AW}^{5}$ \\
\hline Tratamento & & $<.0001$ & $<.0001$ & $<.0001$ & 0.1574 & $<.0001$ \\
\hline Tempo & & $<.0001$ & $<.0001$ & $<.0001$ & 0.0060 & $<.0001$ \\
\hline Interação & & $<.0001$ & $<.0001$ & $<.0001$ & 0.3731 & $<.0001$ \\
\hline Tratamento & & $\mathrm{PCA}^{1}$ & $\mathrm{MRS}^{2}$ & $\mathrm{YM}^{3}$ & MacConkey ${ }^{4}$ & $A W^{5}$ \\
\hline $\mathrm{T} 1^{6}$ & & $4,089^{c} \pm 0,52$ & $1,000^{d} \pm 0,00$ & $4,185^{b} \pm 0,51$ & $2,050 \pm 0,17$ & $0,630^{d} \pm 0,07$ \\
\hline $\mathrm{T} 2^{7}$ & & $5,321^{a} \pm 1,17$ & $2,467^{b} \pm 1,66$ & $5,300^{a} \pm 1,44$ & $2,040 \pm 0,14$ & $0,696^{a} \pm 0,08$ \\
\hline$T 3^{8}$ & & $4,301^{b} \pm 1,02$ & $2,611^{a} \pm 1,85$ & $4,432^{b} \pm 0,93$ & $2,000 \pm 0,00$ & $0,685^{b} \pm 0,07$ \\
\hline $\mathrm{T} 4^{9}$ & & $3,855^{d} \pm 0,09$ & $2,112^{\mathrm{C}} \pm 0,97$ & $3,820^{c} \pm 0,62$ & $2,148 \pm 0,28$ & $0,667^{\mathrm{c}} \pm 0,08$ \\
\hline Tempo (dias) & & $\mathrm{PCA}^{1}$ & $\mathrm{MRS}^{2}$ & $\mathrm{YM}^{3}$ & Mac Conkey ${ }^{4}$ & $A W^{5}$ \\
\hline 0 & & $4,790 \pm 0,78$ & $3,650 \pm 1,73$ & $4,848 \pm 0,96$ & $2,213 \pm 0,32$ & $0,552 \pm 0,01$ \\
\hline 15 & & $4,285 \pm 0,49$ & $2,328 \pm 0,95$ & $4,309 \pm 0,75$ & $2,000 \pm 0,00$ & $0,697 \pm 0,02$ \\
\hline 30 & & $4,074 \pm 0,65$ & $1,213 \pm 0,39$ & $3,936 \pm 0,62$ & $2,025 \pm 0,09$ & $0,731 \pm 0,02$ \\
\hline 45 & & $4,417 \pm 1,58$ & $1,000 \pm 0,00$ & $4,644 \pm 1,58$ & $2,000 \pm 0,00$ & $0,699 \pm 0,07$ \\
\hline
\end{tabular}

*Médias seguidas de mesma letra na coluna são estatisticamente iguais pelo teste de Tukey a $5 \%$ de probabilidade.

'bactérias aeróbias mesófilas; ${ }^{2}$ bactérias láticas; ${ }^{3}$ leveduras; ${ }^{4}$ coliformes totais; ${ }^{5}$ atividade de água; ${ }^{6}$ ração controle (sem kefir); ${ }^{7}$ ração com kefir in natura dessorado $(6,76 \%) ;{ }^{8}$ ração com kefir dessorado e liofilizado aplicado por banho de óleo (1\%); ${ }^{9}$ ração com kefir dessorado e liofilizado incorporado anteriormente à peletização $(1 \%)$. Equações de regressão para tempo: $P C A=0,000943519 x^{2}-$ $0,051330556 x+4,803791667 R^{2}=0,07 ; \quad M R S=0,001231481 x^{2}-0,115850000 x+3,684750000 R^{2}=0,54$; $Y M=0,001385185 x^{2}-0,068900000 x+4,894000000 \quad R^{2}=0,10 ; \quad$ MacConkey $=0,000209259 x^{2}-$ $0,013516667 x+2,198916667 R^{2}=0,21 ; A W=-0,0001973148 x^{2}+0,0120441667 x+0,5545375000 R^{2}=0,78$.

\section{CONCLUSÃO}

A utilização da solução de sacarose $(10 \%)$ como crioprotetor na liofilização proporcionou melhor manutenção de células viáveis de bactérias aeróbias mesófilas e leveduras. Na ração, a maior viabilidade desses microrganismos foi observada 
em kefir dessorado e liofilizado aplicado com banho de óleo (T3). Porém a viabilidade microbiana tendeu decrescer em todos os tratamentos durante a vida de prateleira.

\section{AGRADECIMENTOS}

Instituto Nacional de Ciência e Tecnologia para a Cadeia Produtiva do Leite (INCT-LEITE), Universidade Estadual de Londrina, Rodovia Celso Garcia Cid - Campus Universitário, CP 10011, CEP 86057-970, Londrina, Paraná, Brasil.

\section{REFERÊNCIAS}

AROUTCHEVA, A.; GARITI, D.; SIMON, $M$. et al. Defense factors of vaginal lactobacilli. American journal of obstetrics and gynecology, v. 185, n. 2, p. 375-379, 2001. Disponível em: <https://www.sciencedirect.com/science/ article/pii/S0002937801772353?via\%3Di hub>. Acesso em: 30/10/18.

ARSLAN, S. A review: chemical, microbiological and nutritional characteristics of kefir. CyTA-Journal of Food, v. 13, n. 3, p. 340-345, 2015. Disponível em: $<$ https://www.tandfonline.com/doi/full/10. 1080/19476337.2014.981588>. Acesso em: 16/07/2019.

ATALAR, I; DERVISOGLU, $M$. Optimization of spray drying process parameters for kefir powder using response surface methodology. LWTFood Science and Technology, v. 60, n. 2, p. 751-757, 2015. Disponível em: $<$ https://www.sciencedirect.com/science/ article/pii/S0023643814006446>.

Acesso em: 16/07/2019.

ATTIA, Y. A.; HAMID, E.; EL, A. et al. Nitrate detoxification using antioxidants and probiotics in the water for rabbits. Revista Colombiana de Ciencias Pecuarias, v. 31 , n. 2 , p. $130-$ 138, 2018. Disponível em: < http://www.scielo.org.co/scielo.php?pid=

S0120-

06902018000200130 \&script $=$ sci arttext \&tlng=en>. Acesso em: 16/07/2019.

BHATT, R. S.; AGRAWAL, A. R.; SAHOO, A. Effect of probiotic supplementation on growth performance, nutrient utilization and carcass characteristics of growing Chinchilla rabbits. Journal of Applied Animal Research, v. 45, n. 1, p. 304309, 2017. Disponível em: < https://www.tandfonline.com/doi/full/10.1 080/09712119.2016.1174126>. Acesso em: 16/07/2019.

BRASIL. Ministério da Agricultura, Pecuária e Abastecimento. Instrução Normativa $\mathrm{N}^{\circ} 44$, de 15 de dezembro de 2015. Diário oficial da República Federativa do Brasil. Brasília, DF, 17 de dez de 2015. Seção 1, pág. 7. Disponível em: < http://www.agricultura.gov.br/assuntos/in sumos-agropecuarios/insumospecuarios/produtosveterinarios/legislacao-1/instrucoesnormativas/instrucao-normativa-sdamapa-ndeg-44-de-15-12-

2015.pdf/view>. Acesso em: 10 ago. 2019.

\section{CODEX ALIMENTARIUS} COMMISSION. Milk and Milk Products (CODEX STAN 243-2003), 2 ed. Rome, Italy: World Health Organization (WHO) e Food and Agriculture Organization of the United Nations (FAO), 2011. 248 p.

COOK, M. T.; TZORTZIS, G.; CHARALAMPOPOULOS, D. et al. Microencapsulation of probiotics for gastrointestinal delivery. Journal of Controlled Release, v. 162, n. 1, p. 5667, 2012. Disponível em: <https://www.sciencedirect.com/science/ article/pii/S0168365912004968?via\%3Di hub>. Acesso em: 26/10/18.

COSTA, N. M. B.; ROSA, C. D. O. B. Alimentos funcionais: componentes bioativos e efeitos fisiológicos. 2 ed. 
Rio de Janeiro: Editora Rubio Ltda, 2016. p.161-170.

DE BLAS, C.; MATEOS, G. G. Feed formulation. In: Nutrition of the rabbit 2 ed. de Blas, C.; Wiseman, J. (Eds). CAB International, UK, 2010. p. 222232, 333.

DE PAOLI, P. Biobanking in microbiology: from sample collection to epidemiology, diagnosis and research. FEMS microbiology reviews, v. 29 , n. 5 , p. 897-910, 2005. Disponível em:

$<$ https://academic.oup.com/femsre/articl e/29/5/897/547905>. Acesso em: 05/03/19.

DERTLI, E.; HILMI, A. Microbial diversity of traditional kefir grains and their role on kefir aroma. Food Science and Technology, v. 85, p. 151-157, 2017. Disponível em:

https://www.sciencedirect.com/science/a rticle/pii/S0023643817304966>. Acesso em: 16/07/2019.

DIAS, D. C., LEONARDO, A. F. G., TACHIBANA, $L$. et al. Effect of incorporating probiotics into the diet of matrinxã (Brycon amazonicus) breeders. Journal of Applied Ichthyology, v. 28, n. 1, p. 40-45, 2012. Disponível em: < https://onlinelibrary.wiley.com/doi/full/1 0.1111/j.1439-0426.2011.01892.x>.

Acesso em: 23/05/18.

FULLER, R. Probiotics in man and animals. Journal of Applied Bacteriology, Oxford, v. 66, p. 365-378, $1989 . \quad$ Disponível em: <http://performanceprobiotics.com/Down loads/Articles/Fuller\%201989\%20Probio tics\%20in\%20man\%20and\%20animals. pdf>. Acesso em: 22/05/18.

GARROTE, G. L.; ABRAHAM, A. G.; DE ANTONI, G. L. Microbial Interactions in Kefir: A natural probiotic drink. Biotechnology of lactic acid bacteria: novel applications. Estados Unidos: Blackwell, 2010. p. 327-338.
GIESTING, D. W.; EASTER, R. A. Response of starter pigs to supplementation of corn-soybean meal diets with organic acids. Journal of Animal Science, v. 60 , n. 5, p. 12881294, 1985. Disponível em: <https://pdfs.semanticscholar.org/df9a/8 aa46e5adb0fa371d9c2f8a15f6323d1c79 b.pdf>. Acesso em: 29/10/18.

JAY, J. M. Microbiologia de alimentos. 6.ed. Tradução: Eduardo César Tondo. Porto Alegre: Artmed, 2005. p. 712.

LAUKOVÁ, A.; SIMONOVÁ, M. P.; CHRASTINOVÁ, L'. et al. Benefits of combinative application of probiotic, enterocin M-producing strain Enterococcus faecium AL41 and Eleutherococcus senticosus in rabbits. Folia microbiologica, v. 61, n. 2, p. 169-177, 2016. Disponível em: $<$ https://link.springer.com/article/10.1007 /s12223-015-0423-x>. Acesso em: 16/072019.

LEITE, A. M. D. O.; MIGUEL, M. A. L.; PEIXOTO, R. S. et al. Microbiological, technological and therapeutic properties of kefir: a natural probiotic beverage. Brazilian Journal of Microbiology, v. 44, n. 2, p. 341-349, 2013. Disponível em: < http://www.scielo.br/scielo.php?pid=S15 17-

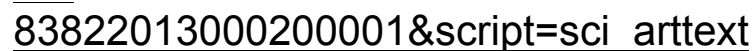
\&tlng=pt $>$. Acesso em: 15/07/2019.

MORGAN, C. A.; HERMAN, N.; WHITE, $P$. A. et al. Preservation of microorganisms by drying; a review. Journal of microbiological methods, v. $66, \mathrm{n}$. 2, p. 183-193, 2006. Disponível em: <https://www.ncbi.nlm.nih.gov/pubmed/1 6632005>. Acesso em: 30/10/18.

OLIVEIRA, M. N. Tecnologia de Produtos Lácteos Funcionais. São Paulo: Atheneu, 2009. p. 384.

POGAČIĆ, T.; ŠINKO, S.; ZAMBERLIN, S. et al. Microbiota of kefir grains. Mljekarstvo, v. 63 , n. 1, p. 3-14, 2013. 
ROCHA, D. M.; MARTINS, J. D.; SANTOS, T. S. et al. Labneh with probiotic properties produced from kefir: development and sensory evaluation. Food Science and Technology, v. 34, p. 694-700, 2014. Disponível em: < http://www.scielo.br/scielo.php?pid=S01 01-

20612014000400008\&script=sci_arttext \&tlng=es>. Acesso em: 16/07/2019.

RODRIGUES, B. M. Inclusão de bactérias probióticas em ração para gatos. 2018. Maringá, 31 f. Dissertação (mestrado em Zootecnia) - Programa de Pós-graduação em Zootecnia, Universidade Estadual de Maringá.

SANTOS, R. B.; DE LIMA BARBOSA, L. P. J.; BARBOSA, F. H. F. Probióticos: microrganismos funcionais. Ciência Equatorial, v. 1, n. 2, 2011. Disponível em:

https://periodicos.unifap.br/index.php/cie nciaequatorial/article/view/562>. Acesso em: 16/07/2019.

SAS Institute Inc. SAS 9.1.3. Help and documentation. SAS Institute Inc., Cary, NC, USA, 2004.

SILVA, A. T. A.; DE OLIVEIRA, S. K. M.; LOCATELLI, G. O. et al. Eficiência de Diferentes Crioprotetores, Empregados $\mathrm{Na}$ Liofilização, Para Preservação de Bactérias Lácticas e Leveduras em Kefir. Blucher Food Science Proceedings, v. 1, n. 1, p. 577-578, $2014 . \quad$ Disponível em: $<$ http://pdf.blucher.com.br.s3-sa-east1.amazonaws.com/foodscienceproceedi ngs/microal/009.pdf>. Acesso em: 30/10/18.

SILVA, K. R.; RODRIGUES, S. A.; XAVIER FILHO, L. et al. Antimicrobial activity of broth fermented with kefir grains. Applied biochemistry and biotechnology, v. 152, n. 2, p. 316-325, 2009. Disponível em: < https://link.springer.com/article/10.1007/ s12010-008-8303-3>. Acesso em: 16/07/2019.
SILVA, P. H. F. Físico-química do leite e derivados: métodos analíticos. Juiz de Fora: oficina de impressão gráfica e editora Itda, 1997. 190 p.

WESCHENFELDER, S.; WIEST, J. M.; CARVALHO, H. H. C. Atividade antiEscherichia coli em kefir e soro de kefir tradicionais. Revista do Instituto de Laticínios Cândido Tostes, v. 64, n. 368, p. 48-55, 2009. Disponível em: $<$ https://www.revistadoilct.com.br/rilct/art icle/view/80/85>. Acesso em 01/11/18.

WESCHENFELDER, S.; PEREIRA, G. D. M.; CARVALHO, $H$. $H$. et al. Caracterização físico-química e sensorial de kefir tradicional e derivados. Arquivo Brasileiro de Medicina Veterinária e Zootecnia. Vol. 63 , n. 2, p. 473-480, 2011. Disponível em:

<https://lume.ufrgs.br/handle/10183/108 512>. Acesso em: 31/10/18.

WITTHUHN, R. C.; SCHOEMAN, T.; 61LLIERS, $A$. et al. Impact of preservation and different packaging conditions on the microbial community and activity of Kefir grains. Food Microbiology, v. 22, n. 4, p. 337-344, 2005. Disponível em: < https://www.sciencedirect.com/science/a rticle/pii/S0740002004001066>. Acesso em: 15/07/2019. 